\title{
Who and Why? Understanding Rural Out-Migration in Uganda
}

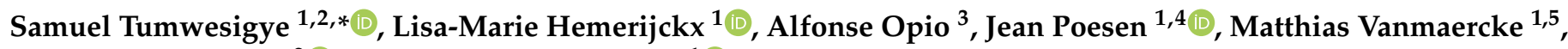 \\ Ronald Twongyirwe $^{2}{ }^{\mathbb{D}}$ and Anton Van Rompaey ${ }^{1}{ }^{1}$
}

1 Division of Geography and Tourism, Department of Earth and Environmental Sciences, KU Leuven, Celestijnenlaan 200E, 3001 Heverlee, Belgium; lisamarie.hemerijckx@kuleuven.be (L.-M.H.); jean.poesen@kuleuven.be (J.P.); Matthias.vanmaercke@kuleuven.be (M.V.); anton.vanrompaey@kuleuven.be (A.V.R.)

2 Department of Environment and Livelihoods Support Systems, Faculty of Interdisciplinary Studies, Mbarara University of Science and Technology, Mbarara P.O. Box 1410, Uganda; rtwongyirwe@must.ac.ug

3 Department of Biology, Faculty of Science, Gulu University, Gulu P.O. Box 166, Uganda; alfonseopio@gmail.com

4 Faculty of Earth Sciences and Spatial Management, Maria-Curie Sklodowska University, Krasnicka 2D, 20-718 Lublin, Poland

5 Department of Geography, UR SPHERES, University of Liège, 4000 Liege, Belgium

* Correspondence: samuel.tumwesigye@kuleuven.be

check for updates

Citation: Tumwesigye, S.; Hemerijckx, L.-M.; Opio, A.; Poesen, J.; Vanmaercke, M.; Twongyirwe, R.; Van Rompaey, A. Who and Why? Understanding Rural Out-Migration in Uganda. Geographies 2021, 1 , 104-123. https://doi.org/10.3390/ geographies 1020007

Academic Editor:

Przemysław Śleszyński

Received: 23 June 2021

Accepted: 23 August 2021

Published: 25 August 2021

Publisher's Note: MDPI stays neutral with regard to jurisdictional claims in published maps and institutional affiliations.

Copyright: (c) 2021 by the authors. Licensee MDPI, Basel, Switzerland. This article is an open access article distributed under the terms and conditions of the Creative Commons Attribution (CC BY) license (https:// creativecommons.org/licenses/by/ $4.0 /)$.

\begin{abstract}
Rural-urban migration in developing countries is considered to be a key process for sustainable development in the coming decades. On the one hand, rural-urban migration can contribute to the socioeconomic development of a country. On the other hand, it also leads to labor transfer, brain-drain in rural areas, and overcrowded cities where planning is lagging behind. In order to get a better insight into the mechanisms of rural-urban migration in developing countries, this paper analyzes motivations for rural-urban migration from the perspective of rural households in Uganda. A total of 1015 rural households located in southwestern Uganda were surveyed in 2019. A total of 48 percent of these households reported having at least one out-migrant. By means of logistic regression modeling, the likelihood for rural out-migration was assessed using household- and community-level socioeconomic characteristics as predictors. The results show that most out-migrants are from relatively wealthy households with a higher-than-average education level. Typically, these households are located in villages that are well connected with urban centers. Poor households in remote locations send significantly fewer migrants because of their limited access to migration information and poor transport networks. From these findings, the following policy recommendations are made: Firstly, efforts should be made to extend basic social services, including quality education, towards rural areas. Secondly, in order to reduce socially disruptive long-distance migration and the eventual overcrowding and sprawls of major cities, government investments should be oriented towards the upgrading of secondary towns, which can offer rural out-migrants rewarding employment and business opportunities.
\end{abstract}

Keywords: rural out-migration; Uganda; spatial analysis; logistic regression

\section{Introduction}

The '2030 Agenda for Sustainable Development' identifies migration as an important pillar and catalyst for sustainable development, especially in the global south [1]. In SubSaharan Africa (SSA), there has been a long history of international and internal migration, with increasing migration rates from and within most of the countries [1,2]. In 2019, 10.4\% of the international migrants (272 million) around the globe originated from the region of SSA [3]. However, a migrant stock of about 763 million people globally (of which $36 \%$ were in SSA) moved within their own countries (internal migration), mainly to urban areas [3]. This indicates that internal rural out-migration is dominant, and this trend in migration is 
predicted to continue into the future given the rural-urban inequality related to the social and economic aspects of life [1].

Generally, the origin-destination inequality in relation to-but not limited to-the labor market, work and business opportunities, wages, social services, and lifestyles is crucial in inducing rural out-migration movements [4]. In spite of people leaving one place for another, migration generally brings the benefits of social and economic development to the origin and destination places alike [2,5]. On the one hand, whenever people move, they transfer manpower and skills, fill the labor market's gaps, and provide knowledge and innovations that contribute to economic growth in the destination places. On the other hand, the migrants send remittances back home, which are used as capital to promote business investments in their communities of origin. In addition, migrants bring cultural diversity to the societies at their destination and, in the case of their return, they take back social remittances in the form of skills and new ideas [5].

This migration-development nexus has long attracted attention at the international level, with many research and policy agendas focusing on international migration [1,6,7]. However, at the national and sub-national levels, as a development issue, migration is also interconnected with social and economic development $[1,8]$. Noteworthy is that the available data and reports that shape migration policy agendas and practices mostly focus on international migration [9]. For example, the 'World Migration Report' published in series since 2000 by the International Organization for Migration (IOM) and the migrant stock dataset from the United Nations Department of Economics and Social Affairs/Population Division (UN-DESA/PD) largely focus on international migration. Going forward, internal migration should also be given more research and policy attention so as to enhance its social and economic development benefits. This is especially valid for the countries of SSA, where this form of migration is dominant and predicted to continue [1,9].

Internal migration can take several forms depending on the direction of the migratory flow: rural to urban, urban to urban, rural to rural, and urban to rural migration [10]. Regardless of the place of destination, if people are moving away from rural areas, this is referred to as rural out-migration. In Uganda, rural out-migration has been an integral part of the development process by contributing to social and demographic changes [11]. During the post-colonial period, the establishment of factories and industries in the urban centers, such as in Kampala and Jinja, presented employment opportunities and induced rural out-migration [12], [13]. In the mid-1990s, the country achieved political stability and subsequently underwent a progressive social and economic transformation [14]. This transformation continues to shape the demographic dynamics in terms of population size, distribution, and urbanization [15].

Growing at an annual average rate of 3\% since 2000, Uganda's total population was estimated to be 44 million in 2020, of which about $76 \%$ is living in rural areas [16]. Although the country is predominantly rural, its urban population is rapidly increasing; it went from 2.9 million in 2002 to 11 million in 2019 [17]. Since 2002, Uganda's average annual urbanization rate of $5.9 \%$ has consistently been higher than that of the rural population growth rate of $2.7 \%$ [17]. This rapid urban population growth is partly driven by in-migration from rural areas. For example, 66 percent of the 1.4 million internal migrants enumerated during the national census of 2014 had permanently settled in urban areas [18]. Uganda's urban centers act as attraction poles for population concentration and distribution, as they offer better social services (education, health, access to clean water and electricity), (potential) business and employment opportunities, and higher wages relative to the rural areas [19]. This rural-urban divide and the inequality in relation to social and economic infrastructures cause the urban areas to be presented as preferred destination for rural out-migrants. As people continue moving from rural to urban areas, it is imperative to better understand the rural out-migration process with respect to who the migrants are, where they migrate to, and why they are moving. Such an understanding is important for informing policy and practice for integrated economic and social relations between the rural and urban areas [9]. 
Additionally, rural out-migration presents development consequences for both the source and the destination areas, which are mostly urban. Although there is no clear-cut definition of what is rural and what is urban, this study adopts the definition of an urban area according to what the Government of Uganda (GoU) lists as a city, municipality, town council, or town board. All of the other localities beyond the administrative boundaries of the listed urban centers are considered rural areas in this study. The rural areas in Uganda are dominated by farming activities, which support the livelihoods of over $89 \%$ of the rural population [20]. Therefore, continued rural out-migration, particularly of the rural youth, would result in a shortage of agricultural labor. This decrease in labor could potentially negatively affect farm productivity [21], as the management of agricultural production increasingly depends on the aging and elderly population. The youth have a relatively greater capacity to apply innovative farming and production practices [22,23]; thus, their rural out-migration would lead rural agricultural households to lose a vital and dynamic share of their workforce. Given this linkage between migration and agriculture in the rural areas of Uganda, it is important to understand the motivations for rural out-migration.

At the destinations, which are mostly urban areas, the influx of rural out-migrants drives urban population growth. When this urbanization process is poorly managed, it contributes to rapid unplanned urban expansion and slum development with the associated negative social, economic, and environmental effects. These effects include crime, congested settlements and traffic, urban poverty, poor sanitation [24,25], and degraded natural resources; for example, papyrus wetlands [26].

Addressing these consequences of rural out-migration requires an evidence-based policy that steers migration towards sustainable forms. This can include promotion of integrated rural and urban development, better-planned and -controlled growth of urban areas, the creation or strengthening of area-based social and economic amenities, and overall integrative rural development in order to empower the social and economic welfare of the rural population. To support such a policy, it is necessary to obtain better insight into the motivations for rural out-migration with an understanding of who out-migrates (or is likely to) and why. The overall objective of this study is, therefore, to gain a better understanding of the motivations for rural out-migration in Uganda. This paper takes the Ankole sub-region in western Uganda as a case study and answers the following research questions.

1. Who migrates? What type of household sends its member(s) as out-migrants?

2. What are the preferred destination areas for the rural out-migrants from the study area?

3. Why rural out-migration? What are the perceived reasons for rural out-migration from the study area?

\section{Study Area}

The study was conducted in the Ankole sub-region in western Uganda (Figure 1). The Ankole sub-region was selected as a case study area because it is representative of many sub-regions in Uganda in terms of out-migration and urbanization rates. During the 2014 national census, the Ankole sub-region had an out-migration rate and urbanization level of $11.2 \%$ and $26 \%$, respectively [18]. This level of urbanization reflects the national average of $25 \%$ [16]. At the time of the survey (i.e., February to August 2019), the sub-region consisted of ten administrative districts (12 in 2020), with an estimated total population of 3.2 million people and a population density of 223 persons $/ \mathrm{km}^{2}$ [16]. The sub-region is predominantly rural, although it has a fast-growing urban population, which grew from $8.2 \%$ in 2014 to $26 \%$ in 2019 [16].

On the one hand, the sub-region's urban structure consists of one city (Mbarara city) with about 300,000 inhabitants, five fast-growing municipalities with a population size of at least 100,000 inhabitants, and 31 town councils with a population size of at least 5000 inhabitants [15]. Mbarara city is a major town that serves as the regional city and is located about $267 \mathrm{~km}$ west of Kampala city (Figure 1). The city, municipalities, and town 
councils serve as centers for administrative, social, and economic services. They host the decentralized and local government administration offices, the health institutions (public and private hospitals), the educational institutions (schools, colleges, and universities), and the economic infrastructures (industries, factories, banks, and markets) [14]. Relative to the rural areas, these towns offer better opportunities for economic participation in both the formal and informal economic sectors.

On the other hand, the rural areas are dominated by farming activities; over $89 \%$ of the households are engaged in subsistence agriculture [20]. Crop farming-mostly bananas and coffee-dominates the agricultural landscape in all districts, apart from in the Kiruhura district, which is dominated by livestock farming. In the Bushenyi and Buhweju districts, a few farmers are undertaking commercial tea growing. In addition, in these two districts, there are four rural-based tea-processing factories that offer employment opportunities, especially to casual laborers from the host and neighboring communities. The Buhweju district also has mineral deposits (mainly gold, tin, and kaolinite), making artisanal mining one of the economic activities in its rural communities.

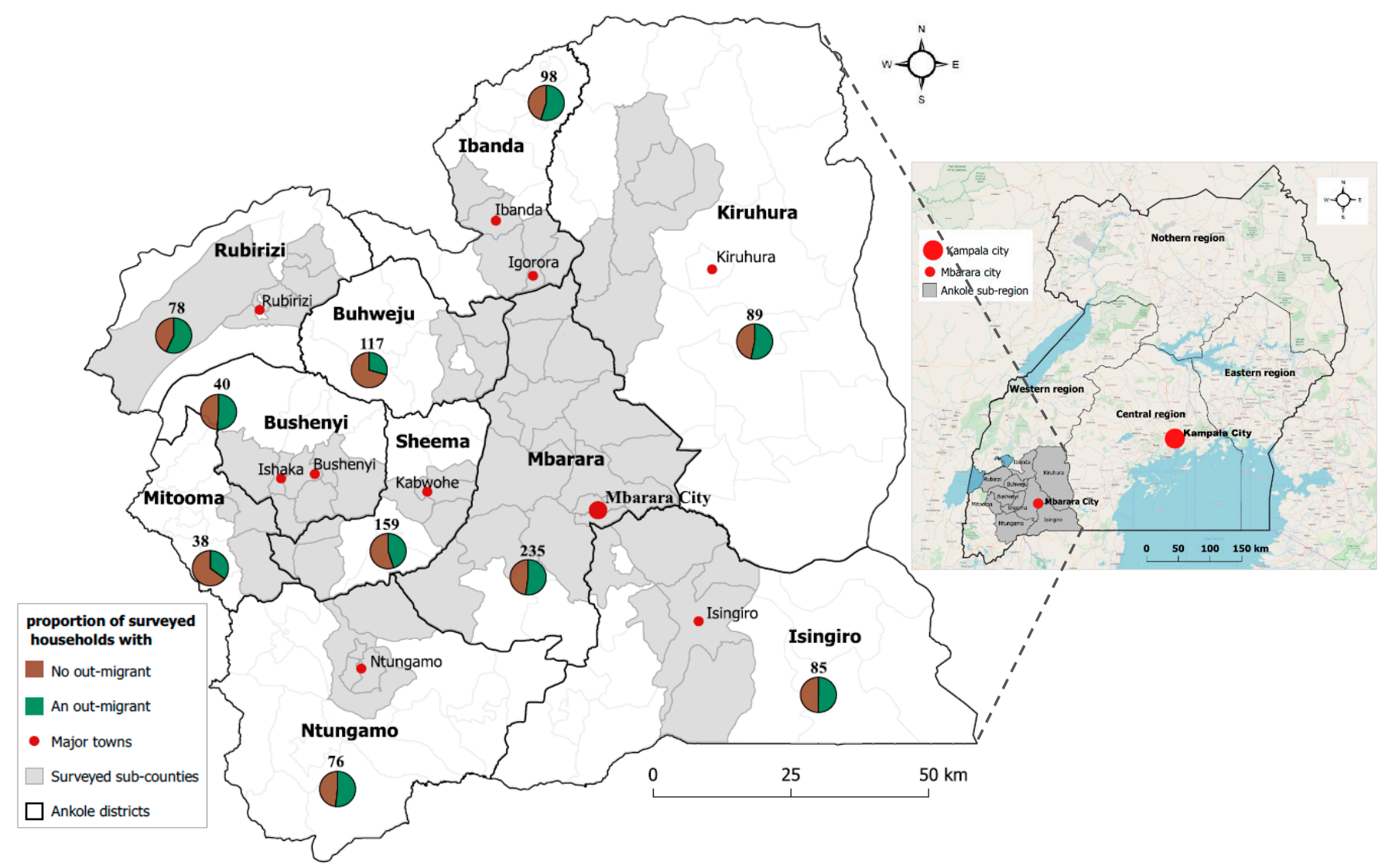

Figure 1. The Ankole sub-region in Western Uganda with the surveyed sub-counties in the 10 districts. Indicated above the pie chart is the number of households surveyed per district $(n=1015)$, while the pie chart shows the proportion of households that reported out-migrants during the survey. Source: authors' compilation from the survey data.

\section{Materials and Methods}

\subsection{Data Collection}

The household-centered New Economics of Labor Migration (NELM) framework [27] and an empirical assertion from a migration study [28] argue that the decision to migrate can be made by all household members together in order to send a member (or members) as migrant(s). Similarly, in this study, we considered the out-migration of a household member to be a collective household decision. Therefore, we collected and analyzed data at the level of a household. We defined a household as a group of people of the same 
family living together in the same housing unit and sharing meals [29] for at least the last 12 months. We considered this period to avoid the inflation of membership due to short-term visitors.

A total of 1015 rural households (Figure 1) located in 61 sub-counties were surveyed between February and August 2019. The sample size per sub-county (a collection of rural villages) was proportional to the corresponding number of households. We preferred sub-counties that were at least connected to the inter-district road network because good road connectivity generally facilitates the movement of people and rural out-migration mobility [30]. The determination of the total sample size for each sub-county followed a modified Cochran formula (Equation (2)) [31]. We computed it by applying a 5\% margin of error and $95 \%$ sampling confidence level to the total households in each sub-county. We used the Cochran formula:

$$
n_{0}=\frac{\mathrm{z}^{2} \mathrm{pq}}{\mathrm{e}^{2}}
$$

where $n_{0}$ is the sample size, $z^{2}$ is the $\mathrm{z}$-value for the $95 \%$ confidence level, $\mathrm{p}$ is the (estimated) proportion of the households with at least one migrant (in this study, $p=50 \%$ ), $q$ is $1-p$, and $\mathrm{e}^{2}$ is the margin of error. Because the total number of households per sampled subcounty was small, we modified Equation (1):

$$
n=\frac{n_{0}}{1+\frac{n_{0}-1}{N}}
$$

where $n$ is the computed sample size and $N$ is total number of households per sampled sub-county.

The sampling frame: Within each sub-county, 4 villages were randomly selected and a list of households per village was created, out of which the households to be surveyed were randomly picked. A list of households per village was obtained from the village administration office (the local council one).

With a team of four trained enumerators, we conducted household-based interviews in the 10 districts of the Ankole sub-region. The enumerators were university graduates and natives and were thus able to fluently communicate in the local language in the study area. Using a structured questionnaire, we collected qualitative and quantitative data on the demographic, social, and economic characteristics at the household and community levels, on the migration history, and on the observed and perceived motivations for outmigration. The questionnaire contained both closed- and open-ended questions, including key (in reference to the study objective) questions on migration; for example, 'If you or any of your household members were to migrate, what would be the reasons, what would be the preferred destination, and, if urban, what category of town would you prefer as your destination?'.

We pre-tested the questionnaire with 40 households in the Mbarara district to ascertain its appropriateness and completeness in capturing the intended survey data. We analyzed the pre-test survey data and accordingly rephrased some questions (particularly on household income) to improve their understandability and clarity. Specifically, we noticed that respondents were sensitive and often uncomfortable about accurately revealing their monthly income. Instead, they could easily provide their consumption expenditures. Moreover, there were no books of records to use to enable the validation of the reported income. Therefore, we considered a household's daily expenditure as an indirect measure of the household's income level [32]. Apart from these data on household income, the rest of the data collected during the pre-test survey were comprehensive and, therefore, considered for analysis in the study.

We traced the sampled households with the guidance of a local guide. We would first explain the study's purpose, seek the respondent's oral consent to be interviewed, and then proceed with the interview. In most cases, the respondents were household heads (80\% male and 20\% female), but in their absence, we interviewed the most senior and knowledgeable household member. For each household, GPS coordinates were taken in the 
event that future follow-up was required. There were no records of refusal or withdrawal from participation in the interviews. Each household interview lasted, on average, $45 \mathrm{~min}$. Generally, the ethical guidelines were adhered to, including free informed consent, the possibility to withdraw at any point, confidentiality, and data security.

\subsection{The Independent Variables Considered in the Study}

The variables considered to estimate the likelihood for a household to have an outmigrant were derived from the reviewed literature. These included variables that describe the demographic, social, and economic characteristics of the household and the community in which the household is located, as well as the physical/environmental factors. The demographic variables included the gender of the household head (male), household size (lager in size), household migration history (yes), age of the household head (older), and dependency ratio (lower ratio), which typically contribute to the household's out-migration likelihood; the status referenced in the parentheses leads to a greater likelihood of a household having an out-migrant $[30,33,34]$. In the case study area, generally, households are headed by males because of the Ankole cultural norms, and household membership is greater than the national average at 4.7 members [17]. In most developing countries, including Uganda, households with a member in remunerative occupation are likely to have out-migrant [35]. Likewise, households with educated members are likely to have out-migrants [30,33]. Over $89 \%$ of the rural households in the study area depend on agriculture as the source of their livelihood; therefore, land is an important asset. As in other developing countries-for example, in Tanzania [30], Ethiopia [33], and Bangladesh [34] - the size of a household's farmland can influence whether a household would send its members as out-migrants. Generally, the bigger the farmland is, the less likely it is for the household to have an out-migrant [30,33]. At the level of the household or household member, income largely shapes many socioeconomic choices and outcomes, including migration decisions [36]. On one hand, the desire to migrate declines as income level is increases [37]. On the other hand, a household with a high income can afford migration costs and is thus likely to have out-migrants [33]. Therefore, the household income level can either facilitate or hinder out-migration. Community-level characteristics that can contribute to a household's out-migration likelihood include the level of remoteness (represented by travel distance to the nearest urban center), availability of social services and infrastructures, as well as the quality of social services provided, availability of natural resources that support livelihoods, and the degree of functioning. Generally, close proximity to an attractive urban center enhances migration [38]. For social services, ready access to and satisfaction with the quality of social services in the community hinder out-migration [39]. Degraded natural resources that can no longer support dependent livelihoods can induce rural out-migration as households seek to diversify or engage in alternative livelihoods [39]. These and additional factors computed from the survey data were fitted in a logistic regression to establish the likelihood of rural out-migration from the Ankole sub-region.

\subsection{Statistical Analysis}

We undertook a descriptive and inferential statistical analysis using the StataMP (version 16) analysis tool. To explore the data descriptively, we computed and compared frequencies, means, and percentages for the surveyed households with a migrant and without a migrant. We undertook cross-tabulation and interpreted the Chi-square statistics to establish the association between the binary variable, 'a household having an out-migrant or not', and the independent variables considered. For the variables that were measured on a continuous scale, we calculated Spearman's correlation statistic. We set the significance level to $p=0.05$ for all of the tests. 
To assess the likelihood of out-migration at the household level, we undertook a logistic regression analysis [40]. In this study, the binary dependent variable is whether or not the household has a migrant. The logistic regression function thus takes the form:

$\mathrm{P}($ household to have an out-migrant $)=\exp \left(\beta_{0}+\beta_{1} X_{1}+\ldots+\beta_{n} X_{n}+\varepsilon_{i}\right) / 1+\exp \left(\beta_{0}+\beta_{1} X_{1}+\ldots+\beta_{n} X_{n}+\varepsilon_{i}\right)$

where $\mathrm{P}$ denotes the probability of a household having an out-migrant, $\beta$ is the regression coefficient, and $X_{1} \ldots X_{n}$ are the independent variables describing the demographic, social, and economic characteristics of the surveyed households and the communities where the households are located. We also considered the physical/environmental factors, such as the natural resource degradation status. We acknowledge that the effects of the interactions of some of these predictor variables would contribute to the likelihood of out-migration from a household; however, when we tested for collinearity, there was no perfect multicollinearity for most variables. In addition, our interest was in establishing the likelihood of out-migration with the effects of all variables considered. The output of this regression function is a probability value between 0 and 1 , which is interpreted as the likelihood for a household to have an out-migrant given the independent variables.

We randomly split the surveyed households into two sub-datasets-one consisting of 811 data cases to allow model fitting, calibration, and estimation, and the other consisting of 204 data cases to allow model validation. We then used the calibration dataset and undertook variable selection and model fitting in three steps. First, we undertook a bivariate analysis for all of the variables. Here, we fitted each variable alone and recorded the corresponding regression estimate and level of significance. Second, regardless of the statistical significance at the bivariate analysis level, we fitted all independent variables into a full multivariate logistic model. We further inspected the model for possible collinearity in the variables for which the interpretability of the estimated coefficients and associated significance levels greatly changed in comparison to the bivariate-level analysis. As such, for any two variables that were found to be correlated, one would be dropped and the other further considered for the reduced final logistic model. Our decision to consider a given variable would be based on the theoretical relevance to the prediction of rural out-migration. Third, we fitted all of the remaining independent and statistically significant $(p<0.05)$ variables into a final reduced logistic model.

The surveyed households were nested within districts; therefore, we expected them to be correlated with each other due to the shared district-level random effects. To account for these district-level random effects, we considered a mixed-effect logistic regression model structure. In addition, to evaluate how well the fitted logistic model estimated the likelihood of a household having an out-migrant, we applied the fitted final reduced logistic model to the validation sub-dataset (204 surveyed households), generated a receiver operating characteristic (ROC) curve, and interpreted the area under the ROC curve (AUC).

\section{Results}

\subsection{Household Demographic Characteristics}

In all of the surveyed households, the membership size ranged from 2 to 14 , with an average of 6.4 (95\% confidence interval (CI), 6.30, 6.57) household members. This household membership reflects the national average of 4.7 members [17]. The average membership sizes for households with a migrant and those without a migrant were 6.7 $(95 \% \mathrm{CI}, 6.65,6.85)$ and $6.2(95 \% \mathrm{CI}, 6.03,6.40)$ members, respectively. Regarding the gender of the household head, there were four times as many male-headed households as femaleheaded households. This ratio was the same among the surveyed households with an out-migrant and those without an out-migrant. A test for the level of association between the gender of the household head and whether the surveyed household had an out-migrant or not indicated that the two variables were independently associated $X^{2}(1, N=811)=$ $0.015, p=0.903$. The number of dependents in the surveyed households ranged from 1 to 9 , with an average of 6 [95\% CI, 5.93, 6.12]. The average number of economically active 
household members (of working age) was 3 [95\% CI, 3.01, 3.22] members. Thus, the average dependency ratio was 2.0 [95\% CI, 1.95, 2.09], implying that every household member of working age had at least two dependents to support. The Mitooma and Bushenyi districts had, respectively, the highest average number of dependents (3.6) and the lowest (2.6; 95\% CI, 2.35, 3.03).

\subsection{Household Social and Economic Characteristics}

The average age of the reported out-migrants was 28 years [95\% CI, 27.89, 29.01], implying that it was the economically active youths that had out-migrated. Ninety-two percent of the reported out-migrants moved to urban areas within the country, whereas $4 \%$ moved to other rural areas, and $4 \%$ were reported as international migrants. When asked how the migration decisions were made, $84 \%$ of the surveyed households with outmigrants responded that the migration decisions were made collectively by the household. Additionally, when asked if any of the household members were likely to out-migrate in the next 12 months, $44 \%$ of the surveyed households indicated that they were likely, $9 \%$ were not sure, and $47 \%$ were unlikely to send an out-migrant. Interestingly, $83 \%$ of the households that already had an out-migrant indicated that they were likely to send another member as an out-migrant.

The most educated members of the majority (74\%) of the surveyed households were in the classification category of literate and (un-)semi-skilled. The Mbarara district had the biggest proportion (22\%) of surveyed households with literate and (un-)semi-skilled members, whereas the Mitooma district had the smallest proportion (4\%). Of the total of 232 households that reported that their most educated member belonged to the literate and skilled category, $62 \%$ were from households that had at least one migrant. Sheema had the biggest proportion ( $23 \%$ ) of surveyed households with literate and skilled members. A test for the level of association between the education level of the most educated household member and whether the surveyed household had a migrant indicated that there was a significant association between a household having an out-migrant or not and the household's educational background $\mathrm{X}^{2}(2, N=811)=22.176, p=0.001$.

Regarding the households' main occupations and livelihood sources, the majority $(67 \%)$ of the surveyed households were engaged in farming activities. This observation was the same within all of the districts of Ankole, where farming was reported as the dominant occupation. Formal employment was reported by $11 \%$ of the surveyed households as their main occupation type. In this occupation category, twice as many surveyed households had an out-migrant $(67 \%)$ compared to those without $(33 \%)$. In contrast, the numbers were almost equal for the other occupation categories (trading and business, formal employment). In addition to the main occupation activities, $63 \%$ of the surveyed households reported diversifying their household income sources. Some of the secondary income sources mentioned included artisanal mining (specifically in the Buhweju district), sand mining, stone quarrying, brick making, occasional wage employment, and remittances. Despite the income diversification, only $55 \%$ of all of the surveyed households could afford a daily consumption expenditure of above 1.9 USD per person (the World Bank's international poverty line).

In relation to the farming occupation, $97 \%$ of the surveyed households owned their farmland, while 3\% were renting. The average land holding per surveyed household was $4.7[95 \%$ CI, 4.45, 5.06] acres. A comparison at the district level revealed that households in Kiruhura had the largest average land holdings of 6.5 [95\% CI, 5.05, 8.03] acres, while the Rubirizi district had the smallest with 3.2 [95\% CI, 2.39, 3.94] acres. The main land-use types reported were crop fields, pastures, plantation forests, and built-up areas, such as homesteads. There were no reported cases of abandoned land. Regarding the status of land productivity, 69\% of the surveyed households reported an observed decrease in land productivity in the last 5 years. The majority $(72 \%)$ of the respondents in the farming occupation also mentioned that their agriculture-based livelihoods were no longer sustainable due to the declining agricultural productivity and the degradation of natural 
resources. Because of this, they reported that they engaged in alternative activities to support their livelihoods, including migration.

The house types (used as a proxy indicator of the household's standard of living) recorded in the study area included temporary, semi-permanent, and permanent houses. About half of the surveyed households were residing in permanent houses, while $38 \%$ and $12 \%$ were living in semi-permanent and temporary houses, respectively. Temporary houses were commonly observed in the Buhweju and Rubirizi districts, accounting for $15 \%$ and $17 \%$ of the surveyed households, respectively.

\subsection{Social and Physical Characteristics at the Community Level}

In response to the question, "If you or any of your household members were to migrate, what would be the preferred destination, and if urban, what category of town would you prefer?", 94\% of the surveyed households preferred an urban center, while $6 \%$ mentioned another rural area as their preferred migration destination. Of those that preferred an urban center, $51 \%$ indicated the nearest municipality, while $28 \%, 20 \%$, and $1 \%$ preferred the regional city (Mbarara city), the capital city (Kampala), and international city as their destination towns, respectively.

Given that the nearest municipality was the destination town that was most preferred by the respondents, we generated the shortest road travel distance from the location of the surveyed household to the nearest municipality. The nearest surveyed household was located $3 \mathrm{~km}$ from the nearest municipality, while the furthest was $128 \mathrm{~km}$ away. The average distance to the nearest municipality was $39 \mathrm{~km}$ [95\% CI, 47.19, 51.28] for the households that reported an out-migrant and $63 \mathrm{~km}$ [95\% CI, 60.62, 64.71] for the households that reported no out-migrants.

We also generated the distances to the nearest educational and health institutions. Overall, $40 \%$ of the surveyed households were within a radius of $5 \mathrm{~km}$ from the nearest health center, while $45 \%$ and $15 \%$ of the surveyed households were within a radius of 5-10 km or greater than $10 \mathrm{~km}$, respectively. In five districts (Sheema, Mbarara, Ibanda, Isingiro, and Rubirizi), over half of the respondents were located within $5 \mathrm{~km}$ from a health center. With respect to schools, $22 \%$ of the surveyed households were within a radius of $3 \mathrm{~km}$ from the nearest school (mostly primary school), while $48 \%$ and $30 \%$ were within a radius of 3-5 km or greater than $5 \mathrm{~km}$, respectively, from the nearest school. The average distances to the nearest primary, secondary, and tertiary schools in the study area were 2.9 [95\% CI, 2.74, 3.03], 8.4 [95\% CI, 8.27, 8.63], and $29.7 \mathrm{~km}$ [95\% CI, 28.97, 30.05], respectively. Comparatively, the surveyed households in Sheema and Bushenyi districts were had the shortest distance to a tertiary institution, with average distances of 22.7 [95\% CI, 21.38, $23.01]$ and $26.1 \mathrm{~km}$ [95\% CI, 25.98, 27.14], respectively.

All of the surveyed sub-counties were already connected to the national electricity grid. However, only 35\% of the surveyed households had an electrical supply in their houses. The majority $(65 \%)$ of the surveyed households used alternative lighting and energy sources, including solar sources (24\%), kerosene (33\%), and wood fuel (8\%). The proportion of the surveyed households already connected to the national electricity grid was highest in the Sheema district (67\%) and lowest in the Mitooma district (8\%). Regarding sources of clean water for domestic use, $47 \%$ of the surveyed households were already connected to the national piped water system. Again, Mitooma district had the lowest proportion of households $(24 \%)$ connected to the national piped water supply, while Rubirizi district had the highest proportion (72\%) of the surveyed households.

\subsection{Reasons for the Rural Out-Migration Push}

We categorized the most frequently mentioned reasons for rural out-migration into broad categories: economic, social, and physical/environmental reasons (Figure 2). 


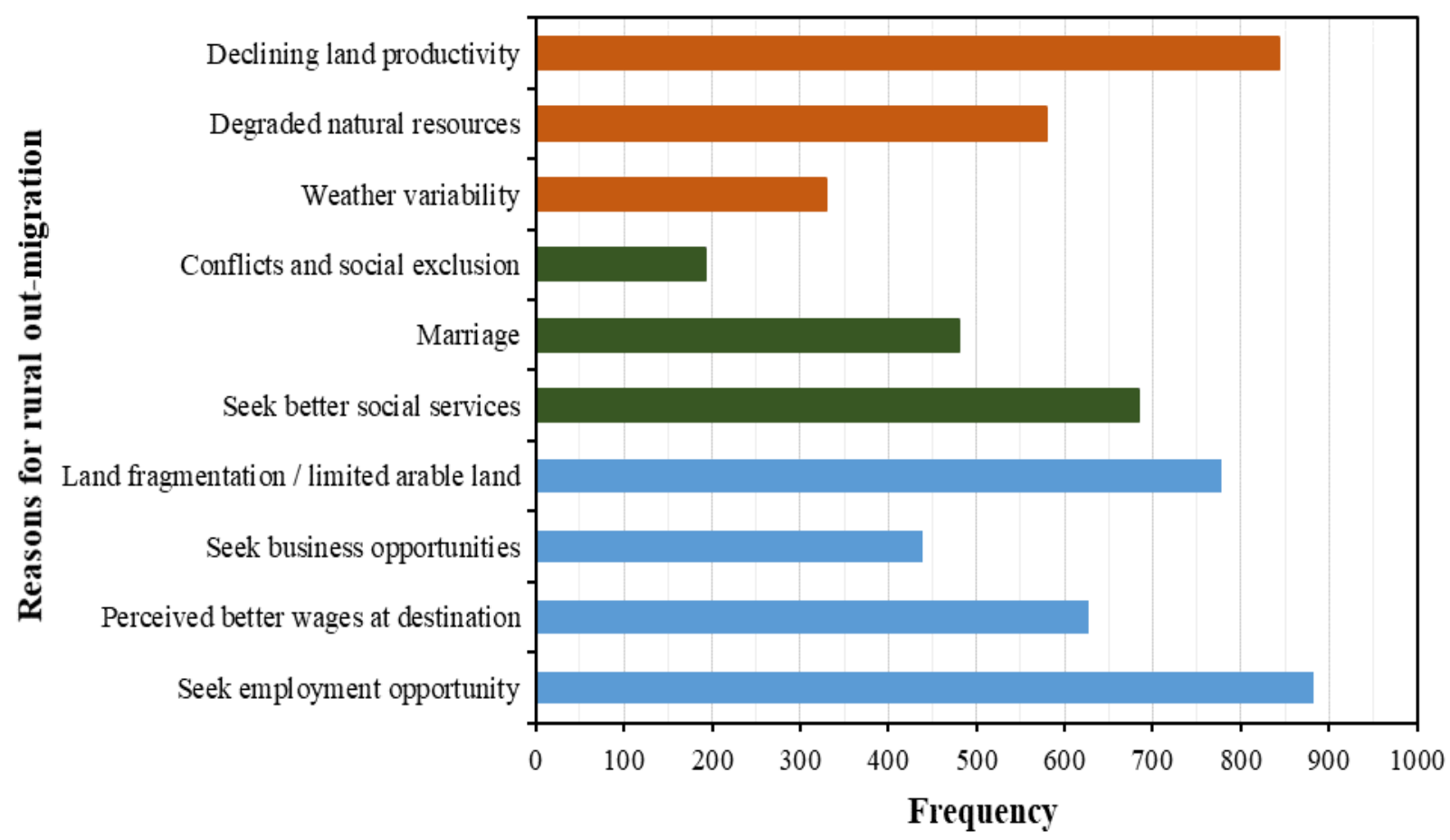

Economic rural push $\quad$ Social rural push $\quad$ Physical environmental rural push

Figure 2. Reported reasons for rural out-migration in the Ankole sub-region in western Uganda. The frequency is a tally of the responses (multiple responses were permitted). Source: authors' compilation from the survey data.

\subsubsection{Economic Reasons for the Rural Push}

The majority ( $87 \%)$ of the respondents-especially the educated-mentioned that they would migrate away from the community and go to other areas where they could find employment and work opportunities. In addition, they mentioned that there is a rural-urban difference in terms of opportunities for productive employment and work, with urban areas offering better opportunities. Moreover, $71 \%$ of the respondents perceived that there were better wages at the migration destinations, which were mostly the urban areas.

Another popular reason mentioned (77\%) for rural out-migration was that arable land was becoming limited, making it difficult for households to generate adequate income from farming activities. The respondents attributed the limitation of sizeable farming land to two factors. First, more agricultural land was required to produce food to feed the rapidly growing population. Second, land sizes were shrinking due to the cultural practice of dividing land among household members, leading to land fragmentation and diminutive plots that could no longer support farming at a scale adequate for sustaining a household's food and financial needs. In addition, $72 \%$ of the respondents in the farming occupation mentioned that their agriculture-based livelihoods were no longer sustainable, and therefore, they engaged in alternative income-generating activities, including business and trade. As such, rural out-migration to seek business and trade opportunities, preferably in urban areas, was another reason mentioned ( $43 \%)$ by the surveyed households.

\subsubsection{Social Reasons for the Rural Push}

The social reasons mentioned for rural out-migration in the Ankole sub-region included seeking better social services, marriage, and freeing from conflicts and social exclusion. About $67 \%$ of the surveyed households mentioned the (perceived) easier access to social services and infrastructures as a reason for rural out-migration. Out-migration because of marriage was another social reason for rural out-migration $(47 \%)$ mentioned by the surveyed households. In addition, social conflicts and exclusion, especially at the 
household level, were mentioned by $20 \%$ of the surveyed households. These respondents further mentioned land disputes (related to ownership rights and user access) over family land as the major form of social conflict. Social disputes over land as a reason for rural out-migration were mostly mentioned in the Rubirizi (52\%), Buhweju (47\%), and Isingiro $(46 \%)$ districts.

\subsubsection{Physical/Environmental Reasons for the Rural Push}

About $57 \%$ of the surveyed households mentioned that most of the communities' natural resources (including land, swamps, forests, and the Rwizi River catchment) were degraded and could no longer sustainably support their natural-resource-dependent livelihoods, leading them to seek alternative means of making a living, including migration. Rural out-migration induced by degraded natural resources was mostly mentioned by the respondents in the Buhweju (23\%), Ntungamo (22\%), and Isingiro (20\%) districts. Relatedly, $83 \%$ of the surveyed households reported a declining land productivity on their farmed plots due to soil erosion and variability in the weather. They further reported-mostly (51\%) in the Isingiro district-that this declining land productivity contributed to food shortage and reduced income from farming, thereby inducing rural out-migration as a coping strategy.

\subsection{Estimation of the Likelihood of Rural Out-Migration}

The logistic regression estimates and the associated levels of significance for most of the predictors remained consistent in both the bivariate and multivariate analyses (Table 1). This implies a low possibility for the presence of inter-correlation among the predictor variables. The demographic, social, and economic factors of household size, dependency ratio, educational background, main occupation and years spent in the occupation, land size, income level, diversification of income sources, and standard of living were significant in estimating the likelihood of an out-migrant in the households, as hypothesized. At the community level, distance to the nearest town (municipality) and level of satisfaction with the quality of public services and infrastructure were the significant predictors for rural out-migration (Table 1).

Table 1. Logistic regression estimates for the likelihood of a household having an out-migrant. The variable form in parenthesis represents the reference category.

\begin{tabular}{|c|c|c|c|c|}
\hline \multirow{2}{*}{ Predictor Variable (Reference Category) } & \multicolumn{2}{|c|}{ Bivariate-Level Analysis } & \multicolumn{2}{|c|}{ Multivariate-Level Analysis } \\
\hline & Odds Ratio & $p$-Value & Odds Ratio & $p$-Value \\
\hline \multicolumn{5}{|l|}{ Gender of household head (female) } \\
\hline Male & $0.909(0.637-1.296)$ & 0.587 & & \\
\hline Age of household head & $1.012(1.004-1.031)$ & 0.008 & & \\
\hline Household size & $1.029(0.967-1.094)$ & 0.048 & $1.065(0.970-1.170)$ & 0.046 \\
\hline Dependency ratio & $0.392(0.321-0.479)$ & 0.001 & $0.399(0.263-0.437)$ & 0.001 \\
\hline Household's migration history (no history) & & & & \\
\hline Has migration history & $1.920(1.297-2.431)$ & 0.970 & & \\
\hline Education level of the most educated member (illiterate) & & & & \\
\hline Primary to high school-literate and (un-)semi-skilled & $0.945(0.684-1.305)$ & 0.729 & $1.182(0.746-1.873)$ & 0.477 \\
\hline Tertiary-level training_-literate and skilled & $1.881(1.285-2.753)$ & 0.001 & 1.776 (1.006-3.134) & 0.048 \\
\hline \multicolumn{5}{|l|}{$\begin{array}{c}\text { Household's main occupation/livelihood source } \\
\text { (farming) }\end{array}$} \\
\hline Trading and business & $1.190(0.831-1.705)$ & 0.342 & $1.504(0.870-2.600)$ & 0.144 \\
\hline Formal employment & $2.254(1.429-3.556)$ & 0.219 & 1.832 (1.132-2.965) & 0.014 \\
\hline Years working in the main household occupation & $1.013(1.000-1.103)$ & 0.058 & $1.024(1.003-1.047)$ & 0.027 \\
\hline Household's land size & $1.178(1.122-1.235)$ & 0.001 & $1.127(1.053-1.207)$ & 0.001 \\
\hline \multicolumn{5}{|l|}{$\begin{array}{l}\text { Household income level: consumption expenditure as a } \\
\text { proxy measure (expenditure of }<1.9 \text { USD/day/person) }\end{array}$} \\
\hline Household's expenditure of $>1.9$ USD/day/person & $1.327(0.049-2.496)$ & 0.046 & $1.597(0.938-2.718)$ & 0.048 \\
\hline $\begin{array}{l}\text { Diversification of household income source (no) } \\
\text { Household has diversified income sources }\end{array}$ & $0.639(0.478-0.854)$ & 0.003 & $0.735(0.477-1.131)$ & 0.043 \\
\hline
\end{tabular}


Table 1. Cont.

\begin{tabular}{|c|c|c|c|c|}
\hline \multirow{2}{*}{ Predictor Variable (Reference Category) } & \multicolumn{2}{|c|}{ Bivariate-Level Analysis } & \multicolumn{2}{|c|}{ Multivariate-Level Analysis } \\
\hline & Odds Ratio & $p$-Value & Odds Ratio & $p$-Value \\
\hline \multicolumn{5}{|l|}{$\begin{array}{l}\text { House type: proxy of standard of living (permanent } \\
\text { house type-good standard of living) }\end{array}$} \\
\hline Semi-permanent: medium standard of living & $0.469(0.306-0.718)$ & 0.001 & $0.331(0.186-0.588)$ & 0.001 \\
\hline Temporary: -poor standard of living & $0.984(0.463-0.662)$ & 0.936 & $0.445(0.246-0.804)$ & 0.007 \\
\hline Distance to the nearest town-municipality & $0.949(0.938-0.960)$ & 0.001 & $0.949(0.936-0.962)$ & 0.001 \\
\hline Distance to the regional city-Mbarara city & $0.964(0.747-1.243)$ & 0.021 & & \\
\hline \multicolumn{5}{|l|}{$\begin{array}{l}\text { Satisfaction level with the quality of public services and } \\
\text { infrastructures in the community (dissatisfied) }\end{array}$} \\
\hline Averagely satisfied with the quality & $0.286(0.193-0.423)$ & 0.001 & $0.322(0.194-0.533)$ & 0.001 \\
\hline Satisfied with the quality & $0.096(0.061-0.150)$ & 0.001 & $0.099(0.056-0.175)$ & 0.001 \\
\hline \multicolumn{5}{|l|}{ Status of natural resources in the community (degraded) } \\
\hline No degradation & $1.763(0.722-4.305)$ & 0.213 & & \\
\hline Electrical supply in the community (no connection) & & & & \\
\hline There is supply and connection & $1.455(1.059-2.000)$ & 0.021 & $1.060(0.670-1.677)$ & 0.805 \\
\hline Piped water supply in the community (no connection) & & & & \\
\hline There is supply and connection & $1.277(0.968-1.683)$ & 0.084 & & \\
\hline Access to a health center (near (within $5 \mathrm{~km}$ )) & & & & \\
\hline Far from a health center (above $5 \mathrm{~km}$ away) & $0.780(0.524-1.160)$ & 0.219 & & \\
\hline Access to education institution (near (within $5 \mathrm{~km}$ )) & & & & \\
\hline $\begin{array}{c}\text { Far from any school institution (above } 5 \mathrm{~km} \text { away) } \\
\text { Constant }\end{array}$ & $1.344(0.925-1.953)$ & 0.120 & $1.924(0.626-5.914)$ & 0.254 \\
\hline
\end{tabular}

\subsubsection{Household-Level Factors}

We found that an additional household member could result in chances of having an out-migrant that were 1.07 times greater. A unit increase in the dependence ratio decreased the likelihood for out-migration by a factor of about 0.39 . Households whose head or most members were in formal employment had 1.83 times greater chances of having an out-migrant compared to those mainly preoccupied by farming activities. Relatedly, an additional year spent undertaking the household's main occupation increased the likelihood of having an out-migrant by a factor of 1.02. Regarding the households' educational backgrounds, households with at least one graduate of a tertiary education institution were 1.78 times more likely to have an out-migrant than those with illiterate members.

We used the households' daily expenditures as an indirect measure of their income levels and found that households that could afford a daily expenditure of more than 1.9 USD per member were 1.60 times more likely to have an out-migrant than households whose daily expenditures was below that threshold. Households who diversified their income sources were $26 \%$ more likely to have an out-migrant than those who did not. Households that were characterized as having either medium or poor standards of living had lower chances of sending an out-migrant by 0.33 or 0.45 times, respectively, compared with those with a good standard of living. Regarding the size of the land owned by the households, we estimated that an additional hectare of land increased the likelihood of a household having an out-migrant by a factor of 1.13 .

\subsubsection{Community-Level Factors}

An additional kilometer away from the nearest municipal town lowered ( 0.95 times) the chances of a household having an out-migrant. Regarding the households' perceived levels of satisfaction with the quality of public services and the state of public infrastructures in the community, we found that households that were generally satisfied with the quality of the public services were less likely to have an out-migrant. A household with an average perceived level of satisfaction with the quality of public service within the community was 0.32 times less likely to have an out-migrant than a household that expressed dissatisfaction. In addition, a household that expressed satisfaction was 0.10 times less likely to have an out-migrant than a household that was dissatisfied. 


\subsection{Performance Evaluation of the Fitted Model}

The plot of the coefficients estimated from the application of the fitted logistic model to the validation sub-dataset resulted in an ROC curve with an AUC of 0.86 (Figure 3). This AUC approached 1, indicating that this was a well-fitted model with overall robust estimation power for household out-migration.

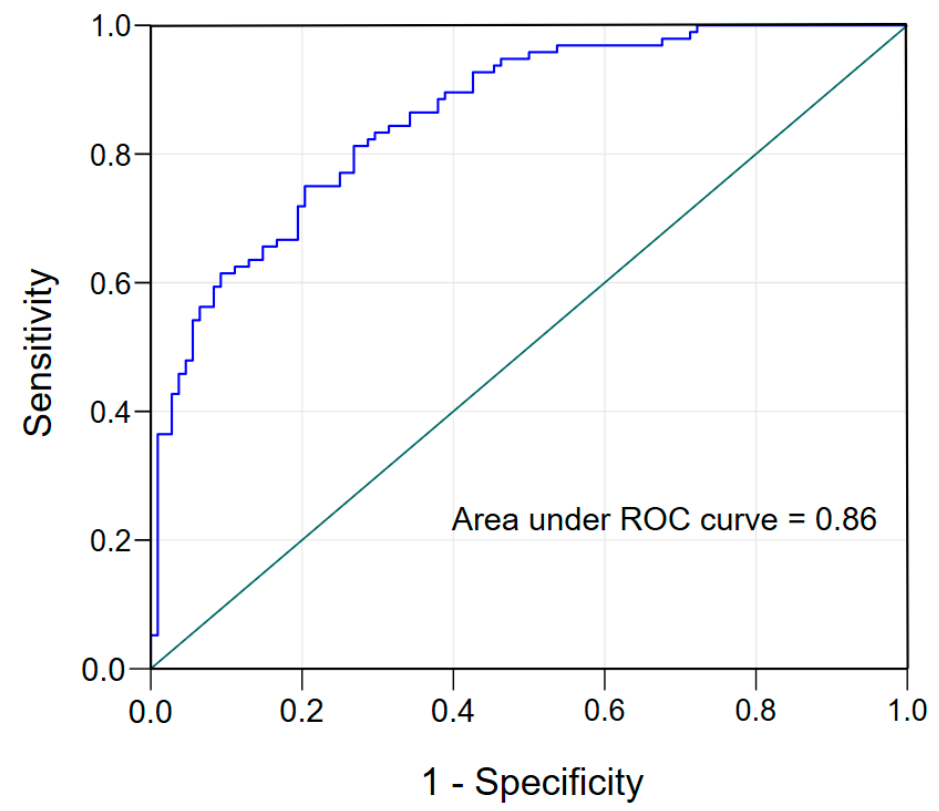

Figure 3. ROC curve and AUC for the logistic model for estimating the likelihood of a household having an out-migrant in the Ankole sub-region. Source: authors' compilation from analysis of the survey data.

Furthermore, the comparison of the estimated likelihood of out-migration and the observed (during the field survey) occurrence of out-migration showed consistency for the surveyed households (Figure 4). It is interesting to note that the households that were located in remote rural areas were both observed and predicted to have a low likelihood of having an out-migrant. Close proximity to the municipal town enhanced the likelihood of a household having an out-migrant (Section 4.5.2). Relative to rural areas, towns generally offer better welfare, social services, and opportunities for work, employment, business, and trade. Therefore, they act as attractive centers for rural dwellers who are searching for better social services and livelihood opportunities. Another observation was that households that were located relatively far away from the main road network were both observed and predicted to have a low likelihood of having an out-migrant. This observation highlights the role of the road network in enhancing local mobility and facilitating the travel of people, thereby promoting rural out-migration. 

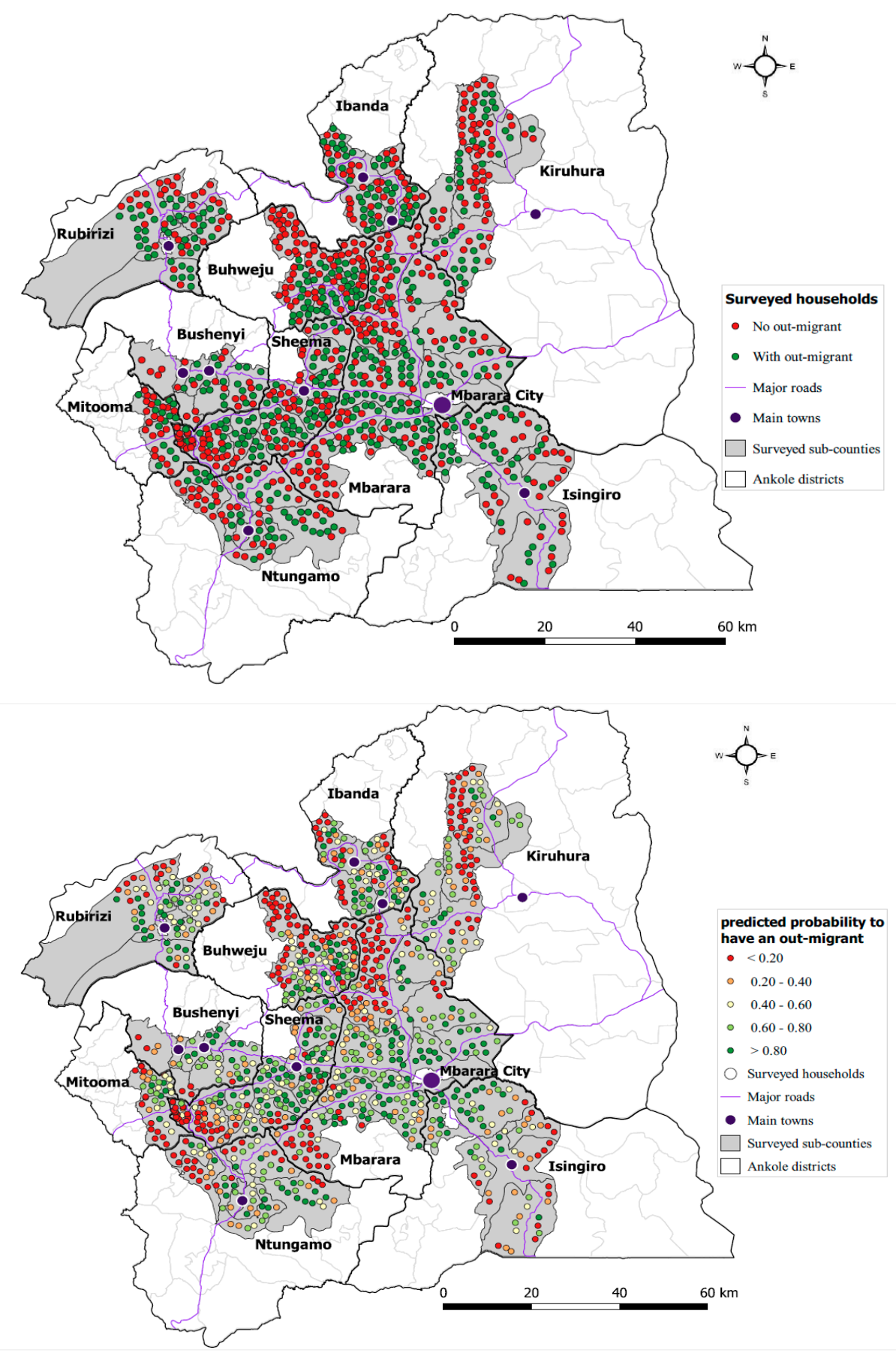

Figure 4. Spatial distribution of the surveyed households showing their corresponding (upper) observed status of having an out-migrant and (lower) predicted likelihood of having an out-migrant. $n=1015$. Source: authors' compilation from the survey data.

\section{Discussion}

5.1. Understanding Who Out-Migrates

\subsubsection{Household Demographic Factors}

The results indicate that larger-sized households had significantly greater chances of having an out-migrant than smaller-sized ones. This could be explained by the allocation of labor among members of the household. The larger the household is, the more flexible the labor force at their disposal will be. This implies that such households can send out their members (as out-migrants) without experiencing serious labor constraints. A larger 
household size also increases the scale of care and responsibility for the household head in providing basic needs. As a coping strategy, adult household members may be allowed to leave to eventually reduce the number that would otherwise require direct support. This effect of household size on out-migration is consistent with findings from migration studies in western and eastern African countries, which asserted that larger families are more likely to have out-migrants $[9,30,33,41-43]$.

Generally, the dependency ratio has a negative correlation with migration likelihood. In the Ankole sub-region, a larger dependency ratio significantly decreases the chances of a household having an out-migrant. The household dependents are usually of minor or elderly ages, and therefore, their prevalence in the household reduces the general mobility of the household members. Uganda has a population pyramid with a wide base, and the proportion of children below the age of 18 in 2019 was 47\% [16]. This young population entirely depends on support from the household heads for their basic needs, which is why most do not leave their families to live independently until they become adults and join the labor force. At the individual level, migration could be driven by the search for independence, freedom, and economic self-sufficiency [44], which are pursued mostly after adulthood. The findings of our analysis agree with the results of similar studies-for example, in Ethiopia [33] and Ghana [43], where smaller dependency ratios were found to foster rural-urban migration.

\subsubsection{Household-Level Social and Economic Factors}

The educational level was a positive and significant predictor of the likelihood of a household having an out-migrant. Education qualification is an indicator of the employability of an individual [30], suggesting that people who are educated possess the knowledge and skills required to perform work in both formal and informal sectors. This, therefore, makes them more likely to move away from their rural homes in pursuit of work opportunities. This is a common observation in Uganda [17], where young, educated adults leave their families in pursuit of their professional careers and end up permanently settling in urban areas, where they mostly work. In addition, young adults pursuing education, especially those enrolled in tertiary institutions, relocate to urban areas where most of these institutions (including universities) are concentrated. After graduation, the majority of them do not return to their rural homes. Instead, they seek employment and start their careers in new places-especially in the capital city and regional towns-where they eventually establish their own families. Likewise, even graduates who do not pursue formal employment but opt to start their own businesses do so in urban areas, where they eventually settle [17]. Moreover, households with an educated member are likely to have extended social networks and can easily access information about migration opportunities that may be leveraged to support migration movements. In addition, educated household members have greater social capital, which supports them when they migrate. Previous empirical findings on the determinants of rural-to-urban migration-for example, in Ethiopia [41], Bangladesh [34], and Tanzania [45]—reported a higher likelihood of rural-to-urban migration among households with a high education level.

Generally, rural households with a head in a productive occupation are likely to have migrants [35]. In the Ankole sub-region, households with members in formal employment or engaged in business and trading can steadily generate daily/monthly income, in contrast to households with a farming occupation, which generate income seasonally. Therefore, the former households may have relatively higher disposable income and can more easily afford potential migration costs. Moreover, households that have spent more time in productive occupations would generally have accumulated wealth assets. Because of this, they might be more capable of meeting the costs of migration and settlement at the out-migrant's destination. This finding is in agreement with the results of a study in Ghana, which reported higher out-migration rates among salary-earning households compared to those in self-employment [35]. Similarly, in Bangladesh, members from households 
with non-agricultural occupations were more likely to migrate than those in farming occupations [34].

The migration process largely requires financial support to meet the costs associated with the preparation, travel, and settlement at the place of destination. This implies that a household that sends out a member should be able to adequately meet the associated migration costs. As such, a household with a relatively higher income can afford the cost of out-migration and the financial support required for settlement at the destination. Similarly, a household characterized by a good standard of living is generally perceived as wealthier; therefore, it would already have accumulated wealth assets that can generate adequate finances for meeting the migration costs. As such, poorer households would be less likely have out-migrants. These findings are consistent with research outcomes in India [46], Ethiopia [33], and Bangladesh [34], which showed that the households sending migrants were those with relatively higher income levels.

In developing countries, migration is generally an income diversification strategy of rural households [47]. In the Ankole sub-region, households that had diversified income sources were found to be less likely to have an out-migrant. The possible explanation is that the household members who would potentially out-migrate are already engaged in diversification activities, thus decreasing the likelihood of the household sending an out-migrant. Households without diversified income sources would still consider sending out a household member for employment, work, business, and trade opportunities as an alternative means of household income generation.

Farmland size significantly increased the chances of a household having an outmigrant. The household farmland size determines the scale of farmed plots, the farming possibilities, and, thus, the level of income generated from farming activities. Households that own large-sized lands tend to engage in commercial farming. These households can generate a relatively high income from their farming activities. Thus, they can afford to hire labor and meet the labor costs; therefore, they do not necessarily depend on family labor. Moreover, such households may be able to afford the migration costs more easily in the case of any out-migration decisions.

\subsubsection{Community-Level Structural Factors}

The general observation is that rural out-migration in developing countries is partly driven by structural factors at the community level, including the availability of education and health services, roads and communication networks, and access to and regular supply of basic utilities, such as electricity and water [5,9,48]. In Namibia, the authors of [44] highlighted that rural-to-urban migration is considered as an opportunity to extricate oneself from the hardships of rural life and the structural constraints of the 'village box'. Similarly, the absence of basic public services that are essential to the welfare of people in the communities of the Ankole sub-region would push households or household members to migrate to other areas in search of such services. The existence of inequality related to social and economic infrastructures in rural Ankole versus the urban areas would induce the movement of people, especially those seeking to reduce what they see as the inequality between their own communities and the target destinations.

Regarding the road connectivity and proximity to a town, we showed that a household located closer to a municipality is more likely to have an out-migrant than a household that is located further. We explain this effect of distance in two ways. First, the urban pull effect may facilitate migration from households that are located close to urban centers, as the travel distances and the associated costs are smaller. Second, the urban push effect of the horizontally expanding municipalities may lead to the reclassification of rural (agricultural) areas as urban land. This process often goes along with livelihood changes, and households that were previously located in peri-urban areas may not easily adapt to the 'new' urban lifestyle. Consequently, these households experiencing the 'urban push effect' might migrate or send out members as migrants. 


\subsection{Understanding the Reasons for Rural Out-Migration}

Generally, there is a noticeable rural-urban difference in economic and social welfare in Uganda [11,49]. Most urban areas are production hubs for goods and services and serve as centers for trade and business. Relative to rural areas, the urban areas present a better chance for a higher quality life because they offer better social services-they have higherquality educational institutions and are more equipped health units, steady electricity supplies, and piped water networks [49]. Therefore, rural populations who seek better education, health services, employment, work, business, and trade opportunities would be attracted to the urban centers. Moreover, work opportunities in urban areas offer better remuneration than those in rural areas, with young wage earners and salaried workers in urban areas earning an average of 259,000 Ugandan shillings (about 70 USD) per month, whereas their counterparts in rural areas obtain an average of 172,000 Ugandan shillings (about 46 USD) per month [17]. This rural-urban divide in relation to the provision of social services and rewarding employment creates an inequality and induces rural out-migration movements with the hope of reducing the gap between one's own position and that of urban dwellers. In relation to business and trade opportunities, business startups prefer to be located in urban areas in order to benefit from the vertical and horizontal business chain linkages with already-established business enterprises. In addition, 'new' businesses may benefit from the urban consumers' supplementary demand and purchasing behaviors. Moreover, urban centers are more densely populated, thereby presenting a market with a greater consumption demand, implying that businesses located in urban centers are more likely to thrive.

In rural areas, agricultural productivity has been declining, which is partly due to the fragmentation of land and the degradation of the natural resources [20]. Nevertheless, the livelihoods of $89 \%$ of the rural population still depend on subsistence agriculture [20]. This declining agricultural productivity makes it untenable for these rural households to sustain their agriculture-based livelihoods. Therefore, they cope by diversifying into alternative livelihood activities, including migration for work [9]. Relatedly, the rural population in the Ankole sub-region is increasing at an average rate of $2.4 \%$ per year, leading to a high population density (223 persons $/ \mathrm{km}^{2}$ ) [17]. The densification of the rural areas and the cultural practice of dividing family land amongst household members have reduced the farmland per capita in the Ankole sub-region [20]. Consequently, smaller farm plots no longer support farming at a scale that is adequate for sustaining a household's food and financial needs. This may lead to out-migration by the household members in order to spread out the risks of household income generation [9]. In the long run, continued rural out-migration, particularly of the rural youth, will result in a shortage of agricultural labor. This is a situation that would exacerbate the already declining agricultural production and productivity [21], since the management of farms increasingly depends on the aging and elderly population. Therefore, Uganda's agricultural sector would lose its advantage as an engine for rural development and its potential function of supporting agro-based livelihoods for the $78 \%$ of the population that already depends on that sector.

Generally, to understand who out-migrates and why from the perspectives at the origin (rural areas), we find that the demographic, social, economic, and physical/ environmental characteristics at the household and community levels, as well as the social and economic attributes of the household members (potential out-migrants), are all important in influencing out-migration decisions and movements. In some instances, the effects contributed by each of these factors could be from individual factors on their own or due to an interaction effect, as explained in a study on the narratives of rural migration in contemporary Namibia [44]. In this study, we did not explore the interaction effects of different contributing factors, though some factors, such as the land size owned by the household, could influence the household income level depending on the land-based income generation activities that a household is involved in. Our study's scope did not extend to cover such interaction effects; however, we recommend that any studies ensuing from our work should take this into consideration. 


\section{Conclusions}

In this study, we estimated the likelihood of a rural household sending an out-migrant and gained insight into who out-migrates from the rural areas in the Ankole sub-region of Uganda. We found that poorer households involved in subsistence farming and those located in remote rural areas were less likely to have an out-migrant. Generally, rural out-migrants were more likely to come from larger, wealthier households with educated and (semi-)skilled members. Households that sent out migrants were located in areas with good road networks, and were also in close proximity to urban centers, especially the municipalities of the sub-region. This study also inquired about the preferred destination places of rural out-migrants and found that the majority preferred the nearest municipality over the capital city, Kampala.

A synthesis of the perceived motivations for rural out-migration revealed the major reasons to be seeking employment and business opportunities, seeking better social services, and diversification of household income sources. These reasons relate to the rural-urban social and economic divide, as well as to the fact that the majority of rural households can no longer sustain their agriculture-based livelihoods due to environmental degradation. We therefore assert that rural out-migration from the Ankole sub-region is primarily a livelihood strategy. Although rural out-migration in developing countries is commonly considered to be a livelihood strategy for the poorest rural dwellers [9], this study asserts that rural out-migrants are more likely to come from better-off households that can adequately support the migration process. Therefore, rural out-migration from the Ankole sub-region in particular and from rural Uganda in general is not necessarily for the poorest sections of the communities, but also for the better-off households, which seek to diversify their means of making a living/household income generation through rewarding employment and business opportunities. The rural-urban inequality in relation to social services, work, employment, and business opportunities also contributes to the likelihood of rural out-migration.

Therefore, this study points out two policy implications for integrated rural development in Uganda. The first is the enhancement of wellbeing and human capital development in rural areas by extending and improving the infrastructures that provide the basic social services related to health, education, clean water, electricity, transportation, and communication. Second, in order to reduce socially disruptive long-distance migration, which leads to overcrowding and sprawls in the major cities, urban development investments should be oriented towards the upgrading of secondary towns, which are the most preferred migration destinations and offer rewarding employment and business opportunities.

Author Contributions: Conceptualization and methodology, S.T., A.V.R., M.V. and R.T.; software, S.T., A.V.R., M.V. and L.-M.H.; validation, S.T.; formal analysis and investigation, S.T. and A.V.R.; resources and data curation, S.T.; writing-original draft preparation, S.T.; writing-review and editing, S.T., A.V.R., R.T., J.P., L.-M.H. and A.O.; visualization, S.T. and A.V.R.; supervision, A.V.R., R.T., J.P. and A.O.; project administration, A.V.R., R.T., J.P. and A.O.; funding acquisition, A.V.R. All authors have read and agreed to the published version of the manuscript.

Funding: This study was conducted under a VLIR-UOS (Vlaamse Interuniversitaire Raad-Universitaire Ontwikkelings Samenwerking [Flemish Inter-University Council-University Development Cooperation])-funded TEAM project between KU Leuven and Mbarara University of Science and Technology in Uganda. The project aims to strengthen the research and education capacity at the latter educational institution. The authors are, therefore, grateful to the VLIR-UOS for the financial support.

Institutional Review Board Statement: The study was conducted according to the National guidelines for research involving humans in Uganda, and was approved by both the Research and Ethics Committee of Mbarara University of Science and Technology and the Uganda National Council for Science and Technology (UNCST). The study's registration and clearance number is NS147ES. 
Informed Consent Statement: As a requirement under UNCST guidelines, an informed consent form was part of the study tools. Prior to the household survey, respondents would be taken through the form's content and their informed consent obtained.

Data Availability Statement: This study used data collected from household surveys conducted by the authors. It doesn't use any publically archived datasets. We have no any public data availability link to provide.

Acknowledgments: The authors are thankful to all households that participated in the survey and the field enumerators who conducted household surveys. Additionally, we are grateful to the anonymous reviewers, whose contributions and suggestions greatly improved the study conceptualization and results discussion.

Conflicts of Interest: The authors declare no conflict of interest.

\section{References}

1. IOM (International Organization for Migration). World Migration Report 2020. In Report 2020; International Organization for Migration: Geneva, Switzerland, 2020.

2. Naudé, W. The Determinants of Migration from Sub-Saharan African Countries. J. Afr. Econ. 2010, 19, 330-356. [CrossRef]

3. UNDESA [United Nations Department of Economic and Social Affairs]. International Migration 2019. In Report 2019; United Nations Department of Economic and Social Affairs: New York, NY, USA, 2019.

4. Black, R.; Natali, C.; Skinner, J. Migration and inequality. In Development Research Centre on Migration, Globalization and Poverty Paper 2005; University of Sussex: Brighton, UK, 2005.

5. IOM [International Organization for Migration]. Global Migration Indicators 2018. In Report 2018; International Organization for Migration: Berlin, Germany, 2018.

6. Skeldon, R. International Migration, Internal Migration, Mobility and Urbanization: Towards More Integrated Approaches. In IOM Migration Research 2018; International Organization for Migration: Geneva, Switzerland, 2018.

7. Champion, A.G. International Migration and Demographic Change in the Developed World. Urban Stud. 1994, 31, 653-677. [CrossRef]

8. Landau, L.B.; Kihato, C.W. The Future of Mobility and Migration Within and From Sub-Saharan Africa. In EU Policy Paper; Princeton University Press: Princeton, NJ, USA, 2018. Available online: http://arks.princeton.edu/ark:/88435/dsp013b591c36x (accessed on 18 September 2020).

9. FAO [Food and Agriculture Organization of the United Nations]. Rural Africa in Motion: Dynamics and Drivers of Migration South of the Sahara. In Report 2017; FAO and CIRAD: Rome, Italy, 2017. Available online: http://www.fao.org/3/i7951en/I795 1EN.pdf (accessed on 10 June 2020).

10. IOM [International Organization for Migration]. World Migration Report 2015: Migration and Cities: New Partnerships to Manage Mobility. In Report 2016; International Organization for Migration: Geneva, Switzerland, 2016.

11. Mukwaya, P.; Bamutaze, Y.; Mugarura, S.; Todd, B. Rural-urban transformation in Uganda. J. Afr. Dev. 2012, 14, 169-194.

12. Mulumba, D.; Olema, W.M. Mapping Migration in Uganda. Policy Analyses Report from IMMIS-African Migration and Gender in Global Context: Implementing Migration Studies. In Report 2009; Makerere University: Kampala, Uganda, 2009.

13. Lyons, M. 'Foreign Bodies': The history of labour migration as a threat to public health in Uganda. In African Boundaries: Barriers, Conduits and Opportunities 1996; Nugent, P., Asiwaju, A.I., Eds.; Pinter: London, UK, 1996.

14. MoFPED [Ministry of Finance Planning Economic Development]. State of Uganda Population Report 2018; Ministry of Finance Planning Economic Development: Kampala, Uganda, 2018.

15. ADB [Africa Development Bank]. Africa Economic Outlook 2019; Africa Development Bank: Abidjan, Côte d'Ivoire, 2019.

16. UBOS [Uganda Bureau of Statistics]. Statistical Abstract 2020; Uganda Bureau of Statistics: Kampala, Uganda, 2020.

17. UBOS. Statistical Abstract 2019; Uganda Bureau of Statistics: Kampala, Uganda, 2019.

18. UBOS. National Census Report 2016; Uganda Bureau of Statistics: Kampala, Uganda, 2016; pp. 2-3. [CrossRef]

19. Tumwesigye, S.; Vanmaercke, M.; Hemerijckx, L.-M.; Opio, A.; Poesen, J.; Twongyirwe, R.; Van Rompaey, A. Spatial patterns of urbanisation in Sub-Saharan Africa: A case study of Uganda. Dev. South. Afr. 2021. [CrossRef]

20. MAAIF [Ministry of Agriculture Animal Industry and Fisheries]. 2019/2020 Sectoral Performance Report. In Report 2020; Ministry of Agriculture Animal Industry and Fisheries: Entebbe, Uganda, 2020.

21. Gollin, D. Agricultural transformation and urbanisation in Uganda. In Policy Note; International Growth Centre: Kampala, Uganda, 2016.

22. FAO. Youth and Agriculture: Key Chnallenges and Concrete Solutions. In Report 2014; Food and Agriculture Organization of the United Nations: Rome, Italy. Available online: http:/ / www.fao.org/3/a-i3947e.pdf (accessed on 25 May 2020).

23. Herren, H.R.; Bassi, A.M.; Zhuohua, T.; Binns, P.W. Green Jobs for a Revitalised Food and Agriculture Sector. In Working paper 2012; Food and Agriculture Organization of the United Nations: Rome, Italy, 2012.

24. Tacoli, C.; Mcgranahan, G.; Satterthwaite, D. Urbanisation, rural-urban migration and urban poverty Acknowledgements. In Working Paper; IIED: London, UK, 2015. Available online: www.iied.org@iied (accessed on 29 July 2020). 
25. Vermeiren, K.; Van Rompaey, A.; Loopmans, M.; Serwajja, E.; Mukwaya, P. Urban growth of Kampala, Uganda: Pattern analysis and scenario development. Landsc. Urban Plan. 2012, 106, 199-206. [CrossRef]

26. Ryken, N.; Vanmaercke, M.; Wanyama, J.; Isabirye, M.; Vanonckelen, J.; Deckers, J.; Poesen, J. Impact of papyrus wetland encroachment on spatial and temporal variabilities of stream flow and sediment export from wet tropical catchments. Sci. Total Environ. 2015, 511, 756-766. [CrossRef] [PubMed]

27. Stark, O.B.; Bloom, D.E. The New Economics of Labor Migration. Am. Econ. Rev. 1985, 75, 173-178.

28. De Brauw, A.; Mueller, V.; Lee, L.H. The Role of Rural-Urban Migration in the Structural Transformation of Sub-Saharan Africa. World Dev. 2012, 63, 33-42. [CrossRef]

29. Scoones, I. Livelihoods perspectives and rural development. J. Peasant. Stud. 2009, 36, 171-196. [CrossRef]

30. Duda, I.; Fasse, A.; Grote, U. Drivers of rural-urban migration and impact on food security in rural Tanzania. Food Secur. 2018, 10, 785-798. [CrossRef]

31. Bartlett, J.E.; Kotrlik, J.W.; Higgins, C.C. Organizational Research: Determining Appropriate Sample Size in Survey Research. Inf. Technol. Learn. Perform. J. 2001, 19, 43.

32. Pape, U.; Mistiaen, J. Household Expenditure and Poverty Measures in 60 Minutes: A New Approach with Results from Mogadishu; World Bank Policy Paper No 8430; World Bank: Washington, DC, USA, 2018. Available online: https: / / openknowledge.worldbank.org/ handle/10986/29836 (accessed on 16 April 2020).

33. Tegegne, D.A.; Penker, M. Determinants of rural out-migration in Ethiopia: Who stays and who goes? Demogr. Res. 2016, 35, 1011-1044. [CrossRef]

34. Hossain, M.Z. Determinants of Rural-Urban Migration in Bangladesh including its Consequences for Origin Households and Urban Amenities. J. Stat. 2016, 5, 47-61.

35. Clotilde, M.; Wim, N. Migration, occupation and education: Evidence from Ghana. In UN-MERIT Working Paper; UNU-MERIT: Maastricht, The Netherlands, 2016. Available online: https://migration.unu.edu/publications/working-papers/migrationoccupation-and-education-evidence-from-ghana.html (accessed on 10 March 2020).

36. OECD/European Union. Income of immigrant households. In Indicators of Immigrant Integration 2015; OECD Publication: Paris, France, 2015. [CrossRef]

37. Beegle, K.; De Weerdt, J.; Dercon, S. Migration and economic mobility in Tanzania: Evidence from a tracking survey. Rev. Econ. Stat. 2011, 93, 1010-1033. [CrossRef]

38. Mandel, A.; Ferrero, V.O.; Graser, A.; Bruy, A. QGIS 2 Cookbook: Become a QGIS Power User and Master QGIS Data Management. In Visualization, and Spatial Analysis Techniques; Packt Publishing: Birmingham, UK, 2016.

39. Bilsborrow, R.E.; DeLargy, P.F. Land Use, Migration, and Natural Resource Deterioration: The Experience of Guatemala and the Sudan. Popul. Dev. Rev. 1990, 16, 125-147. [CrossRef]

40. Kleinbaum, D.G.; Klein, M. Logistic Regression: A Self-Learning Text. Int. Stat. Rev. 2010, 79, 296.

41. Eshetu, F.; Beshir, M. Dynamics and determinants of rural-urban migration in Southern Ethiopia. J. Dev. Agric. Econ. 2017, 9, 328-340. [CrossRef]

42. Kafle, K.; Benfica, R.; Winters, P. Does relative deprivation induce migration? Evidence from sub-Saharan Africa. Am. J. Agric. Econ. 2017, 102, 999-1019. [CrossRef]

43. Tsegai, D. Migration as a Household Decision: What are the Roles of Income Differences? Insights from the Volta Basin of Ghana. Eur. J. Dev. Res. 2007, 19, 305-326. [CrossRef]

44. Venditto, B. The construction of the self: Narratives of rural migration in contemporary Namibia. Africa N. S. 2019, 1, 97-118.

45. Ocello, C.; Petrucci, A.; Testa, M.; Vignoli, D. Environmental aspects of internal migration in Tanzania. Popul. Environ. 2015, 37, 99-108. [CrossRef]

46. Chakraborty, D.; Kuri, P.K. The Household Level Determinants in the Choice and Level of Migration: A Micro Study in West Bengal. Environ. Urban. Asia 2017, 8, 94-104. [CrossRef]

47. Abizu, S.O. Migration as a Livelihood Diversification Strategy of Poor Rural Household in Edo State, Nigeria. Int. J. Humanit. Soc. Sci. 2018, 8, 79-85. [CrossRef]

48. Castelli, F. Drivers of migration: Why do people move? J. Travel Med. 2018, 25, 1-7. [CrossRef]

49. UBOS. Statistical Abstract 2018; Uganda Bureau of Statistics: Kampala, Uganda, 2018. 